\title{
The dependence of contrail formation on the weather pattern and altitude in the North Atlantic
}

Article

Accepted Version

Irvine, E.A., Hoskins, B.J. and Shine, K.P. (2012) The dependence of contrail formation on the weather pattern and altitude in the North Atlantic. Geophysical Research Letters, 39 (12). L12802. ISSN 0094-8276 doi:

https://doi.org/10.1029/2012GL051909 Available at https://centaur.reading.ac.uk/28899/

It is advisable to refer to the publisher's version if you intend to cite from the work. See Guidance on citing.

Published version at: http://dx.doi.org/10.1029/2012GL051909

To link to this article DOI: http://dx.doi.org/10.1029/2012GL051909

Publisher: American Geophysical Union

All outputs in CentAUR are protected by Intellectual Property Rights law, including copyright law. Copyright and IPR is retained by the creators or other copyright holders. Terms and conditions for use of this material are defined in the End User Agreement.

www.reading.ac.uk/centaur 
Central Archive at the University of Reading

Reading's research outputs online 


\section{The dependence of contrail formation on the weather pattern and altitude in the North Atlantic}

E. A. Irvine, ${ }^{1}$ B. J. Hoskins, ${ }^{1,2}$ K. P. Shine ${ }^{1}$

B. J. Hoskins, Grantham Institute for Climate Change, Imperial College London, Exhibition Road, South Kensington, London, SW7 2AZ, UK.

E. A. Irvine, Department of Meteorology, University of Reading, Earley Gate, Reading, RG6 6BB, UK. (e.a.irvine@reading.ac.uk)

K. P. Shine, Department of Meteorology, University of Reading, Earley Gate, Reading, RG6 6BB, UK.

${ }^{1}$ Department of Meteorology, University

of Reading, Reading, UK.

${ }^{2}$ Grantham Institute for Climate Change, Imperial College London, London, UK. 
${ }_{3} \quad$ Aircraft flying through cold ice-supersaturated air produce persistent con-

${ }_{4}$ trails which contribute to the climate impact of aviation. Here, we demon-

${ }_{5}$ strate the importance of the weather situation, together with the route and

6 altitude of the aircraft through this, on estimating contrail coverage. The re-

7 sults have implications for determining the climate impact of contrails as well

s as potential mitigation strategies. Twenty-one years of re-analysis data are

9 used to produce a climatological assessment of conditions favorable for per-

${ }_{10}$ sistent contrail formation between 200 and $300 \mathrm{hPa}$ over the north Atlantic

${ }_{11}$ in winter. The seasonal-mean frequency of cold ice-supersaturated regions

${ }_{12}$ is highest near $300 \mathrm{hPa}$, and decreases with altitude. The frequency of oc-

${ }_{13}$ currence of ice-supersaturated regions varies with large-scale weather pat-

${ }_{14}$ tern; the most common locations are over Greenland, on the southern side

${ }_{15}$ of the jet stream and around the northern edge of high pressure ridges. As-

${ }_{16}$ suming aircraft take a great circle route, as opposed to a more realistic time-

${ }_{17}$ optimal route, is likely to lead to an error in the estimated contrail cover-

${ }_{18}$ age, which can exceed $50 \%$ for westbound north Atlantic flights. The prob-

${ }_{19}$ ability of contrail formation can increase or decrease with height, depend-

${ }_{20}$ ing on the weather pattern, indicating that the generic suggestion that fly-

${ }_{21}$ ing higher leads to fewer contrails is not robust. 


\section{Introduction}

${ }_{22}$ Cold ice-supersaturated regions (ISSRs) are climatically important. An aircraft flying

${ }_{23}$ through such regions will form a contrail, which may persist for many hours and even

${ }_{24}$ spread to become indistinguishable from natural cirrus. The present-day climate impact

25 of these man-made clouds is estimated to be between $10-80 \mathrm{~mW} \mathrm{~m}^{-2}$ [Lee et al., 2009],

${ }_{26}$ potentially greater than that of aviation $\mathrm{CO}_{2}$ emissions (estimated at $28 \mathrm{~mW} \mathrm{~m}^{-2}[$ Lee

${ }_{27}$ et al., 2009]).

${ }_{28}$ Ice-supersaturation is a relatively common feature of the upper troposphere; in-situ

${ }_{29}$ measurements of relative humidity from specially-instrumented commercial aircraft found

so ice-supersaturation in $13.5 \%$ of the data, with a mean supersaturation of $15 \%$ [Gierens

31 et al., 1999]. Satellite data provide a global view of the distribution of ISSRs, revealing

32 maxima in the storm track regions and near the tropopause at high latitudes [Spichtinger

3з et al., 2003a; Lamquin et al., 2012].

${ }_{34}$ The motivation for this study is to link the distribution of ISSRs to specific large-

35 scale weather patterns. Previous studies show that ISSRs may be found in anticyclonic

36 flow [Kästner et al., 1999; Immler et al., 2008], above a warm conveyor belt of a cyclone

${ }_{37}$ [Spichtinger et al., 2005a] or caused by gravity waves [Spichtinger et al., 2005b]. These

${ }_{38}$ observationally-based studies necessarily use small local domains and short observational

39 time periods or individual case studies and therefore the results may not be representative

40 of larger mid-latitude regions. A climatological assessment of the occurrence of cold ISSRs

${ }_{41}$ over the north Atlantic region is presented Section 3.1; this is related to large-scale weather

42 patterns in Section 3.2. 
Previous work has investigated the possibility of mitigating the climate impact of con-

${ }_{44}$ trails by changing aircraft cruise altitudes [Williams et al., 2002; Mannstein et al., 2005;

${ }_{45}$ Fichter et al., 2005; Rädel and Shine, 2008]. This is based upon ISSRs being shallow fea-

${ }_{46}$ tures; radiosonde observations of ISSR depth over the United Kingdom show a peak value

${ }_{47}$ of $50 \mathrm{~m}$ [Rädel and Shine, 2007]. For the northern hemisphere mid-latitudes, increasing

${ }_{48}$ the cruise altitude of aircraft on average reduces the number of contrails that would be

${ }_{49}$ formed [Fichter et al., 2005], as more flights then occur in the comparatively dry strato-

so sphere; however, in Sections 3.2 and 3.3 we show that it is important to consider both the

${ }_{51}$ altitude and the weather pattern together with the likely path of the aircraft to determine

${ }_{52}$ whether a change in altitude will reduce or increase the probability of contrailing.

53 One, perhaps surprising, difficulty in determining the climate impact of contrails is that

${ }_{54}$ an accurate description of where aircraft fly is not readily available. Compiled inventories

${ }_{55}$ of aircraft movement often use great circle routes (or assume a simple distribution around

${ }_{56}$ them) to approximate true aircraft routes; more recent inventories use radar data where

${ }_{57}$ available but must still use great circle routes over areas such as the North Atlantic where

${ }_{58}$ there is no radar coverage [Owen et al., 2010; Wilkerson et al., 2010]. Aircraft routes

${ }_{59}$ over the North Atlantic vary greatly from day-to-day depending on the strength of the

60 jet stream, and eastbound and westbound routes can differ significantly [Irvine et al.,

${ }_{61} 2012$ ]; in Section 3.3 it is demonstrated how this may introduce an error into estimates of

${ }_{62}$ contrail coverage which use great circle routes.

\section{Data}


Cold ISSRs are identified as regions with a relative humidity with respect to ice above $100 \%$ and a temperature below 233K (to avoid regions of supercooled water clouds).

${ }_{65}$ Such a temperature threshold is broadly consistent with the Schmidt-Appleman criterion

${ }_{66}$ [Schumann, 1996] for contrail formation for an aircraft engine with an efficiency of 0.3 .

${ }_{67}$ For this study, ISSRs were identified in the European Centre for Medium-Range Weather

${ }_{68}$ Forecasts (ECMWF) Re-analysis Interim data (ERA-Interim; Dee et al. [2011]) over the

${ }_{69}$ north Atlantic flight corridor (here taken to be the area $35-75^{\circ} \mathrm{N}, 0-70^{\circ} \mathrm{W}$ ). The data were

70 used at $0.7^{\circ}$ horizontal resolution on four pressure levels $(300,250,225$ and $200 \mathrm{hPa}$ )

${ }_{71}$ that span the range of permitted aircraft cruise altitudes. For the climatological analysis

72 (Section 3.1), ISSRs are identified in the 0000 UTC analyses for the period 1989-2010;

${ }_{73}$ the weather pattern analysis (Sections 3.2 and 3.3) uses data for three winters (December

${ }_{74}$ - February) for which optimal route data were available. The use of re-analysis data

75 allowed the analysis of ISSRs over a larger geographical region and for a climatological

76 time period that would not be possible with direct observations. ERA-Interim data are

${ }_{77}$ particularly suited to this study as the model cloud scheme permits ice-supersaturation

78 [Tompkins et al., 2007], although the analyses suffer from a dry bias [Lamquin et al., 2009]

79 and have had limited validation against observational data.

True aircraft flight paths across the Atlantic are approximated using daily time-optimal route data, which are representative of the location of north Atlantic air traffic [Irvine et al., 2012]. These routes minimise the flying time between London and New York, taking into account the winds at $250 \mathrm{hPa}$ and assuming the aircraft flies at a constant speed and

${ }_{84}$ pressure. The data were generated using the Met Office optimal routing software [Lunnon, 
${ }_{85}$ 1992] that was run on $40 \mathrm{~km}$ resolution Met Office Unified Model forecasts. An eastbound

${ }_{86}$ (at 0000 UTC) and a westbound (at 1200 UTC) route are provided for each day of three

${ }_{87}$ winters, 2004-05 2008-09 and 2009-10, which were chosen for their different jet stream

${ }_{8}$ behavior and correspond respectively to positive, neutral and negative seasonal-mean

${ }_{89}$ phases of the north Atlantic oscillation (NAO).

\section{Results}

\subsection{Climatological Frequency of ISSRs}

${ }_{90}$ In the north Atlantic region in winter, the mean frequency of cold ISSRs is $7.1 \%$, with ${ }_{91}$ an overall decrease in frequency with altitude from $8.7 \%$ at $300 \mathrm{hPa}$ to $5.2 \%$ at $200 \mathrm{hPa}$ ${ }_{92}$ (the mean values are obtained by averaging over the north Atlantic region shown in Figure ${ }_{93}$ 1). This decrease above $300 \mathrm{hPa}$ is in agreement with Fichter et al. [2005].

${ }_{94} \quad$ Figure 1 shows spatial variations in the long-term winter-mean frequency of cold ISSRs ${ }_{95}$ in the north Atlantic. Maxima in the frequency of cold ISSRs are found in the storm track ${ }_{96}$ regions and are particularly noticeable at 200 and $250 \mathrm{hPa}$ in the ERA-Interim data. The ${ }_{97}$ higher frequencies at higher altitudes are consistent with the ISSRs occurring south of the ${ }_{98}$ jet stream where the tropopause is higher.

99 The largest frequency of cold ISSRs is over Greenland. This maximum is absent at ${ }_{100} 200 \mathrm{hPa}$ (Figure 1(a)), presumably because at this high latitude air is generally further 101 into the relatively dry stratosphere. Local maxima in ISSR frequency along the coast 102 of Greenland match the location of maxima in gravity wave stress as represented in the ${ }_{103}$ ECMWF system (not shown), suggesting that ISSRs may be formed by the lifting of 104 air past saturation by orographically-generated gravity waves. The minimum in ISSRs at 
${ }_{126}$ the regions south of the jet stream are also evident, particularly for types 2 (Figure $2(\mathrm{~b})$ )

${ }_{127}$ and 3 where the jet stream is located further north; this suggests that the ISSRs are caused

${ }_{128}$ by the slantwise ascent of the warm air in the storms that grow on the jet. Averaged over

${ }_{129}$ all the weather types this gives the general storm track region maximum seen in Figure

${ }_{130}$ 1. In type 4, where the ridge over the Atlantic is most pronounced, high frequencies of ${ }_{131}$ ice-supersaturation are found in the anti-cyclonic flow. This is consistent with the fact ${ }_{132}$ that air travelling northwards around a ridge ascends up the isentropic surface and this ${ }_{133}$ can lead to saturation.

${ }_{134}$ Clearly, in different weather types the frequency of cold ISSRs does not always decrease

with height. Over Greenland it decreases with height, for all weather types except type 4 where the high frequency of cold ISSRs in the ridge over Greenland exhibit little change with height. However, the frequency of cold ISSRs south of the jet stream increases with height; this is clear in type 2, where there is a tilted jet across the Atlantic, and a higher tropopause south of the jet stream. This is particularly important as it shows that whilst earlier results indicating that flying higher produces fewer contrails may be true climatologically, the results do not hold for individual weather patterns. The differences in the distributions of ISSRs for the various weather types show little relationship with the corresponding differences in the mean tropopause locations obtained using a blended tropopause definition [Wilcox et al., 2012].

ISSRs have been observed to be shallow features [Rädel and Shine, 2007; Spichtinger et al., 2003b]; in the limited altitude range considered here, 57-63\% of ISSRs are observed at a single pressure level, depending on the weather type. This indicates that within 
148 the range of aircraft cruise altitudes, small changes in altitude may be sufficient to avoid

149 forming a contrail, corroborating Mannstein et al. [2005].

\subsection{Application to Quantifying Aircraft Climate Impact}

The probability of forming a contrail flying at a particular altitude in a weather pattern

151 is shown in Figure 3, for both great circle and time-optimal routes. This is the fraction of

${ }_{152}$ the total route distance in a cold ISSR, averaged over all days belonging to that weather

${ }_{153}$ type. For great circle routes (Figure 3(a)) the probability of contrailing at a particular

altitude is $1-10 \%$, and there is a range of behavior with height for the different weather

${ }_{155}$ patterns. We note that these probabilities are likely to be biased low, as previously

156 discussed.

${ }_{157}$ In reality, jet stream winds heavily influence the route location, so that it is more appropriate to use time-optimal routes to approximate flight paths across the north Atlantic. 


\section{Discussion and Conclusions}




\section{References

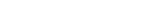

creases with altitude but storm track maxima increase with altitude. This indicates that there is no generic (e.g. 'fly higher') solution to mitigating the climate effects of contrails; any such mitigation decisions would have to be dependent on the weather situation.

In the north Atlantic, the jet stream variability can lead to routes different from the great circle. Whilst the probability of contrailing along an eastbound route is similar to a great circle route, using a great circle route to approximate the path of a westbound flight can overestimate the probability of contrail formation by over $50 \%$ for some commonly occurring weather patterns. This demonstrates the importance of accurate inventories of air traffic movement data, particularly over large oceanic regions with little radar coverage.

The lack of such data forces climate impact studies to make assumptions about aircraft routes, which is a source error in the estimation of the resulting climate impact.

Whilst this study focused on the north Atlantic region, the results are relevant to other mid-latitude regions, particularly those with strong day-to-day variation in the upper-level winds, such as the north Pacific.

Acknowledgments. The time-optimum route data was provided by Lauren Reid and Andrew Mirza at the Met Office. This work is part of the REACT4C project, funded under the EU 7th framework programme, grant ACP8-GA-2009-233772. We thank the reviewers for their helpful comments.

Dee, D. P., et al (2011), The ERA-Interim reanalysis: configuration and performance of the data assimilation system, Q. J. R. Meteorol. Soc., 137, 553-597, doi: 10.1002/qj.828. 

on contrails and related radiative forcing, Meteorol. Z., 14, 563-572.

Gierens, K., U. Schumann, M. Helten, H. Smit, and P.-H. Wang (2000), Ice-supersaturated regions and subvisible cirrus in the northern midlatitude upper troposphere, J. Geophys. Res., 105, 22,743-22,753, doi:10.1029/2000JD900341.

Gierens, K. M., U. Schumann, H. G. J. Smit, M. Helten, and A. Marenco (1999), A distribution law for relative humidity in the upper troposphere and lower stratosphere derived from three years of MOZAIC measurements, Ann. Geophysicae, 17, 1218-1226.

Immler, F., R. Treffeisen, D. Engelbart, K. Krüger, and O. Schrems (2008), Cirrus, contrails, and ice supersaturated regions in high pressure systems at northern mid-latitudes, Atmos. Chem. Phys., 8, 1689-1699, doi:10.5194/acp-8-1689-2008.

Irvine, E. A., B. J. Hoskins, K. P. Shine, R. W. Lunnon, and C. Froemming (2012), Characterizing north Atlantic weather patterns for climate-optimal aircraft routing, Meteorol. Appl., doi:10.1002/met.1291, in press.

Kästner, M., R. Meyer, and P. Wendling (1999), Influence of weather conditions on the distribution of persistent contrails, Meteorol. Appl., 6, 261-271.

Lamquin, N., K. Gierens, C. J. Stubenrauch, and R. Chatterjee (2009), Evaluation of upper tropospheric humidity forecasts from ECMWF using AIRS and CALIPSO data, Atmos. Chem. Phys., 9, 1779-1793, doi:10.5194/acp-9-1779-2009.

Lamquin, N., C. J. Stubenrauch, K. Gierens, U. Burkhardt, and H. Smit (2012), A global climatology of upper-tropospheric ice supersaturation occurrence inferred from the Atmospheric Infrared Sounder calibrated by MOZAIC, Atmos. Chem. Phys., 12, 381-405, 

doi:10.5194/acp-12-381-2012.

Lee, D. S., D. W. Fahey, P. M. Forster, P. J. Newton, R. C. N. Wit, L. L. Lim, B. Owen, and R. Sausen (2009), Aviation and global climate change in the 21st century, Atmospheric Environment, 43, 3520-3537.

Lunnon, R. W. (1992), Optimization of time saving in navigation through an area of variable flow, Journal of Navigation, 45, 384-399.

Mannstein, H., P. Spichtinger, and K. Gierens (2005), A note on how to avoid contrail cirrus, Transportation Research Part D, 10, 421-426.

Owen, B., D. S. Lee, and L. Lim (2010), Flying into the future: aviation emissions scenarios to 2050, Environ. Sci. Technol., 44, 2255-2260.

Rädel, G., and K. P. Shine (2007), Evaluation of the use of radiosonde humidity data to predict the occurrence of persistent contrails, Q. J. R. Meteorol. Soc., 133, 1413-1423, doi:10.1002/qj.128.

Rädel, G., and K. P. Shine (2008), Radiative forcing by persistent contrails and its dependence on cruise altitude, J. Geophys. Res., 113, D07,105, doi:10.1029/2007JD009117.

Schumann, U. (1996), On conditions of contrail formation from aircraft exhausts, Meteor. Z., $5,4-23$.

Spichtinger, P., K. Gierens, and W. Read (2003a), The global distribution of icesupersaturated regions as seen by the microwave limb sounder, Q. J. R. Meteorol. Soc., 129, 3391-3410, doi: 10.1256/qj.02.141.

Spichtinger, P., K. Gierens, U. Leiterer, and H. Dier (2003b), Ice supersaturation in the tropopause region over Lindenberg, Germany, Meteor. Z., 12, 143-156. 
${ }_{253}$ Spichtinger, P., K. Gierens, and H. Wernli (2005a), A case study on the formation and evolution of ice supersaturation in the vicinity of a warm conveyor belt's outflow region, Atmos. Chem. Phys., 5, 973-987, doi:10.5194/acp-5-973-2005.

Spichtinger, P., K. Gierens, and A. Dörnbrack (2005b), Formation of ice supersaturation by mesoscale gravity waves, Atmos. Chem. Phys., 5, 1243-1255, doi:10.5194/acp-5-12432005.

Tompkins, A. M., K. Gierens, and G. Rädel (2007), Ice supersaturation in the ECMWF integrated forecast system, Q. J. R. Meteorol. Soc., 133, 53-63, doi:10.1002/qj.14.

Wilcox, L. J., B. H. Hoskins, and K. P. Shine (2012), A global blended tropopause based on ERA data. Part 1: Climatology, Q. J. R. Meteorol. Soc., 138, 561-575, doi: $10.1002 /$ qj. 951.

Wilkerson, J. T., M. Z. Jacobson, A. Malwitz, S. Balasubramanian, R. Wayson, G. Fleming, A. D. Naiman, and S. K. Lele (2010), Analysis of emission data from global commercial aviation: 2004 and 2006, Atmos. Chem. Phys., 10, 6391-6408, doi:10.5194/acp10-6391-2010.

Williams, V., R. B. Noland, and R. Toumi (2002), Reducing the climate change impacts of aviation by restricting cruise altitudes, Transportation Research Part D, 7, 451-464. 
(a)

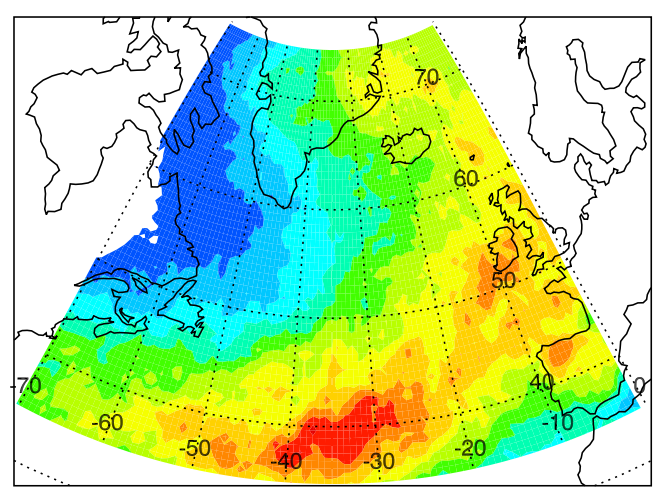

(b)

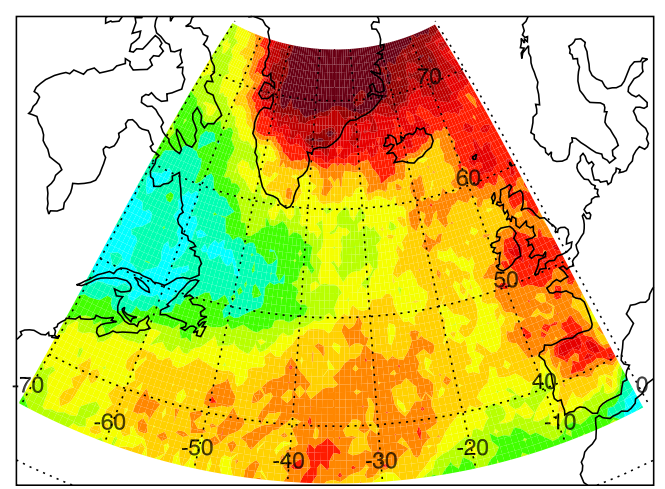

(c)

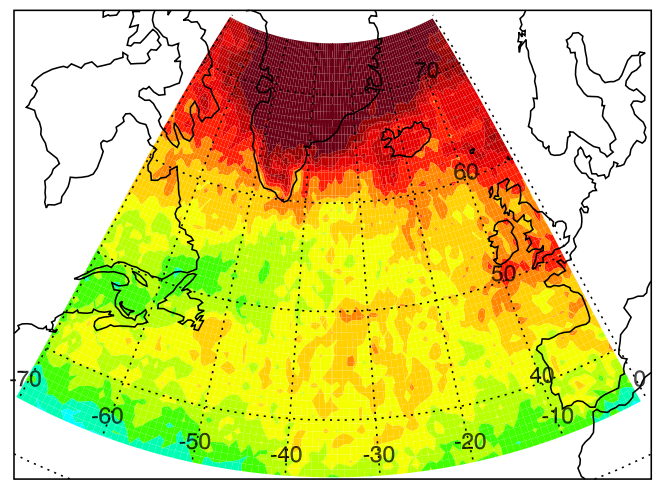

$\begin{array}{lllllllllllll}1 & 2 & 3 & 4 & 5 & 6 & 7 & 8 & 9 & 10 & 11 & 12 & 13 \\ \text { cold ISSR frequency (\%) }\end{array}$

Figure 1. Mean frequency of cold ISSRs at (a) $200 \mathrm{hPa}$, (b) $250 \mathrm{hPa}$ and (c) $300 \mathrm{hPa}$, averaged over all winters in the period 1989 - 2010. 

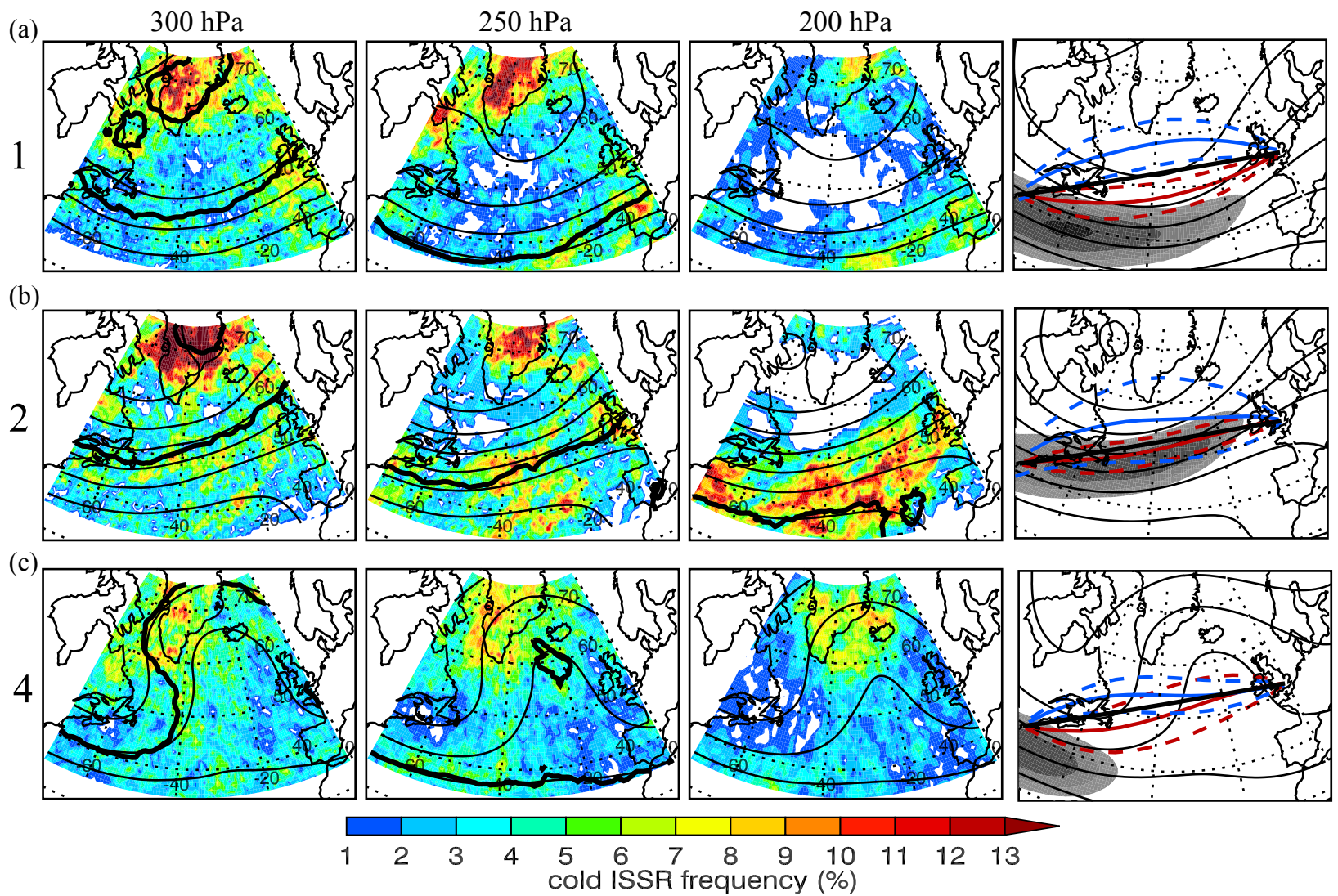

Figure 2. Mean frequency of cold ISSRs, composite geopotential height (thin contours) and tropopause location (thick contour) for days belonging to three of five winter weather types defined in Irvine et al. [2012]: (a) type 1, (b) type 2 and (c) type 4 at $300 \mathrm{hPa}, 250 \mathrm{hPa}$ and $200 \mathrm{hPa}$. The final column shows the mean $250 \mathrm{hPa}$ geopotential height (black contours) and wind speed above $40 \mathrm{~m} \mathrm{~s}^{-1}$ (gray shading, darker shading indicating higher windspeeds, with a contour interval of $3 \mathrm{~m} \mathrm{~s}^{-1}$ ), with the great circle (black line), eastbound time-optimal (red) and westbound time-optimal (blue) routes (both the mean location as solid lines and standard deviation as dashed lines) from days corresponding to each weather type. Calculated using data from winters 2004-05, 2008-09 and 2009-10. 
(a)

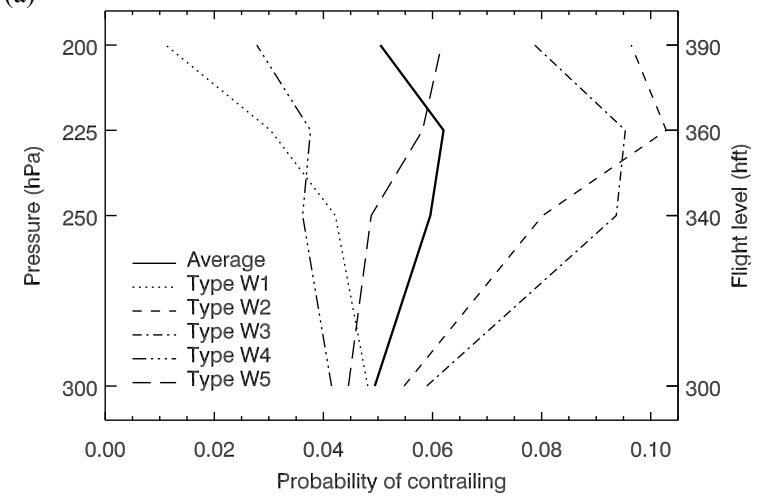

(b)

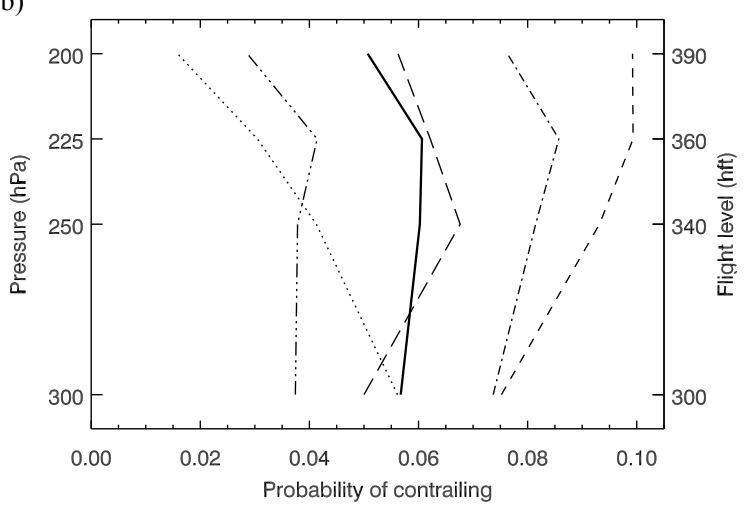

(c)

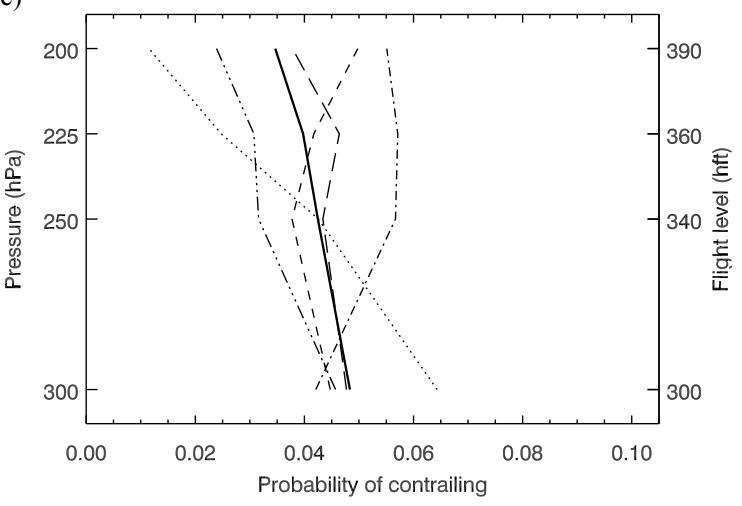

Figure 3. For (a) great circle, (b) eastbound time-optimal and (c) westbound time-optimal routes, the mean probability of making a persistent contrail along the route at different altitudes, averaged over all routes from days corresponding to winter weather type 1 (dotted line), type 2 (short dashed line), type 3 (dash-dot line), type 4 (dash-triple dot line), type 5 (long dashed line) and averaged over all days (solid line). Calculated using data from winters 2004-05, 2008-09 and 2009-10. 